\title{
The preparation and integration of Turkey's National Disaster Response Plan
}

\author{
F. Oktay \\ Republic of Turkey Prime Ministry Disaster and \\ Emergency Management Authority, Turkey
}

\begin{abstract}
Turkey frequently faces disasters that lead to human, material, economic, and environmental losses, interruption of social, economic, and community life, adversely affecting development. Located in one of the most seismically active regions in the world, sixty six percent (66\%) of Turkey's surface area lies on Zones 1 and 2 levels of seismic hazard. Besides earthquakes, urban and rural areas need to consider other natural hazards, mainly landslides, floods, rockfalls, avalanches, that can easily couple with physical, social, economic, and environmental vulnerabilities and turn to costly disasters. Under these conditions Prime Ministry Disaster and Emergency Management Authority (AFAD in Turkish) was established in 2009 as the authorized coordination agency to address all phases of disaster management in Turkey, based on the reorganization of relevant major institutions as well as on the available scientific and practical knowledge, field experience of long years, resources, and technology.

After the Van Earthquake (October 2011), the need for development of an integrated national disaster response plan became an increasingly pressing item on the country's agenda. New studies, approaches, and plans on disaster management emerged, supported by the advancement in technology and increase in public awareness on disasters. Following detailed research on types of events and response needs, AFAD, together with governmental and non-governmental stakeholders, initiated the preparation of the national disaster response plan to define basic principles of action, activities and institutional roles and responsibilities in anticipation of, during and after disasters or emergency situations. The plan is named as Turkey's National Disaster Response Plan
\end{abstract}


(Türkiye Afet Müdahale Planı - TAMP in Turkish) and put to effect upon official approval as at January 2014.

TAMP, with its flexible, modular-structure, is adaptable to all types and scales of hazards and enables effective planning of resources and coordination of public, private institutions and non-governmental organizations in case of a disaster at local or national level to minimize human and material loss.

Keywords: disaster response, integrated disaster response planning, disaster and emergency management.

\section{Introduction}

A disaster is a serious disruption of the functioning of a community or a society involving widespread human, material, economic or environmental losses and impacts, which exceeds the ability of the affected community or society to cope using its own resources [1]. Turkey often faces with disasters triggered by natural hazards, which lead to human, material, economic, and environmental losses because of her geological and geomorphological structure and climatic characteristics [2].

Located in one of the most seismically active regions in the world, sixty six percent $(66 \%)$ of Turkey's surface area lies on Zones 1 and 2 levels of seismic hazard. Between 1900 and 2012 there have been 287 damaging earthquakes, leading to 100,000 deaths while nearly 700,000 buildings were reported having major damages or totally destroyed [3]. Besides earthquakes, urban and rural areas need to consider other natural hazards, mainly landslides, floods, rockfalls, avalanches, that can easily couple with physical, social, economic, and environmental vulnerabilities and turn to costly disasters.

After the Van Earthquake in 2011, AFAD started working for a more effective disaster management policy, covering all phases of integrated disaster management, and preparation of the National Disaster Response Plan became an effective beginning step [4]. Turkey Disaster Response Plan (Türkiye Afet Müdahale Planı - TAMP in Turkish) covers all response action required in case of any disaster or emergency and defines the processes, activities, roles, duties, responsibilities, authorization and cooperation of all stakeholder institutions and communities at national and local levels in detail [5].

TAMP emerged as a result of a two-year study in this context. (See [6] for the main national policy documents searched during preparations of the plan.) Compared to the previous plans, TAMP was handled with a comprehensive approach, the number of service groups was increased, and services were thoroughly integrated. Personnel, equipment and resource analyses are to continue regularly at central and local levels, supported by up-to-date SWOT analysis to help development and improvement of disaster scenarios, appropriate response methods and capacity in all terms. 


\section{The objective and principles of TAMP}

The goal of Turkey's National Disaster Response Plan (TAMP) is to define the roles and responsibilities of the service groups and coordination units taking part in disaster and emergency response and to determine the basic principles of response plan in anticipation of, during and after disasters. TAMP includes the personnel of the ministries, the public instutions, private, and non-governmental organizations.

The four basic principles of TAMP are as follows:

a. Comprehensive approach (considering preparation, response, recovery phases together)

b. To address hazards of all types and scales

c. To cover responsibilites and roles of all key and supportive institutions, partnering to provide solutions

d. To mobilize national, regional in local disaster response capacities for fast and timely response.

The complementary basis for these basic principles, based on legislation, is defined as the establishment of an effective, flexible and scalable structure, considering improvement and further development of coordination and cooperation among all stakeholders, supported by knowledge management and efficient communications.

The objectives of TAMP are stated as follows:

- $\quad$ Saving lives

- $\quad$ Restoring interrupted daily life and activities as soon as possible

- Fast and planned response

- $\quad$ Protect and maintain public health

- $\quad$ Protect property, environment and cultural heritage

- $\quad$ Reduce economic and social losses

- Prevent secondary disasters or mitigate their possible effects

- $\quad$ Ensure efficient use of resources.

\section{Services}

TAMP is based primarily on coordination, cooperation and collaboration. 28 service groups are established under four main service categories (namely, operation, information and planning, logistics and maintenance, finance and administration services) to ensure minimum hierarchy and maximum efficiency in implementation, using a modular structure compatible with the type and size ofthe event. Four main service categories are coordinated under Prime Ministry or AFAD Disaster and Emergency Management Center depending on the severity of the situation.

\subsection{Operation service (Ops)}

This service is the basic unit of response organization and is divided into two subservices according to required of response level and event type: For small- 
scale events Emergency Services sub-service andfor large-scale disasters Early Recovery Services sub-service. These services constitute the first step of the recovery process and form the basis for longer term recovery processes.

\subsection{Information and planning service (I\&P)}

This service is to provide all services necessary for information management, monitoring and evaluation. During the response, this service is responsible for identifying the sources for needed data, data collection and analysis, conducting area reconnaissance, situation reports, situation assessment, and also for preparing alternative strategies based on current data and probability calculations and modelling by analyzing data from geographic information systems (GIS), maps, databases, remote sensors.

\subsection{Logistics and maintenance service (L\&M)}

This service is responsible for establishing facilities, providing the necessary equipment to support all service groups involved in response activities. If the response level declared by AFAD is 2,3 or 4 , the assigned teams need to be selfsufficient and relevant institutions must be ready to meet their personnel, vehicle, equipment, office supplies and social (accommodation, nutrition, hygiene supplies, etc.) needs for "minimum 72, maximum 120 hours".

\subsection{Finance and administration service (F\&A)}

In the scope of the preparedness for response, the financing needs should be stated in the strategic plans of public institutions within the framework of Public Financial Management and Control Law (Law no 5018). For institutions funded through general budget resources, all types of disaster and emergency management investments (met from the general budget) are monitored and coordinated by AFAD. Those institutions that have special budgets and local administrations may allocate a portion of their own budget for disaster and emergency situations. The financial management of emergency needs are made in line with Disaster and Emergency Management Presidency Organization and Duties Law (Law no 5902, article 23) and Disaster and Emergency Expenditures Directive.

\section{Service groups, key and supportive partner institutions}

Ensuring sustainability of interrupted services in disaster and emergency situations requires coordination and organization at Ministrial level. Within this framework, national level service groups are established and for each service a public authority is assigned as a key solution provider. TAMP requires a total of 28 service groups at a national level. These service groups are established according to the needs in emergency and disaster situations. The management of these service groups are assigned to public offices and relevant NGOs (mainly Turkish Red Crescent) according to their field of work. 
Table 1: National level response service groups.

\begin{tabular}{|c|c|c|}
\hline Name of service group & Name of public authority/NGO & $\begin{array}{c}\text { Service } \\
\text { category }\end{array}$ \\
\hline Purchase and lease & AFAD & $\mathrm{F} \& \mathrm{~A}$ \\
\hline $\begin{array}{l}\text { Accounting, budgeting and } \\
\text { financial reporting }\end{array}$ & AFAD & $\mathrm{F} \& \mathrm{~A}$ \\
\hline $\begin{array}{l}\text { National and international } \\
\text { donations (in-cash) }\end{array}$ & AFAD & $\mathrm{F} \& \mathrm{~A}$ \\
\hline Loss assessment (financial) & Ministry of Finance & F\&A \\
\hline $\begin{array}{l}\text { Information management, } \\
\text { evaluation and monitoring }\end{array}$ & AFAD & $\mathrm{I} \& \mathrm{P}$ \\
\hline Service group logistics & AFAD & L\&M \\
\hline $\begin{array}{l}\text { In-kind donations, warehouse } \\
\text { management and distribution }\end{array}$ & $\begin{array}{l}\text { Ministry of Family and Social } \\
\text { Policies }\end{array}$ & L\&M \\
\hline Technical support and supply & $\begin{array}{l}\text { Ministry of Transport, Maritime } \\
\text { Affairs and Communications }\end{array}$ & L\&M \\
\hline Resource management & AFAD & L\&M \\
\hline $\begin{array}{l}\text { International support and } \\
\text { cooperation (supplies, personnel } \\
\text { etc.) }\end{array}$ & AFAD & L\&M \\
\hline Search and rescue & AFAD & Ops \\
\hline CBRN & AFAD & Ops \\
\hline Accomodation (shelter) & AFAD & Ops \\
\hline Energy & $\begin{array}{l}\text { Ministry of Energy and Natural } \\
\text { Resources }\end{array}$ & Ops \\
\hline Damage assessment & $\begin{array}{l}\text { Ministry of Environment and Urban } \\
\text { Planning }\end{array}$ & Ops \\
\hline Infrastructure & $\begin{array}{l}\text { Ministry of Environment and Urban } \\
\text { Planning }\end{array}$ & Ops \\
\hline Debris removal & $\begin{array}{l}\text { Ministry of Environment and Urban } \\
\text { Planning }\end{array}$ & Ops \\
\hline Psychosocial support & $\begin{array}{l}\text { Ministryof Family and Social } \\
\text { Policies }\end{array}$ & Ops \\
\hline Food, agriculture and livestock & $\begin{array}{l}\text { Ministry of Food, Agriculture and } \\
\text { Livestock }\end{array}$ & Ops \\
\hline Health & Ministry of Health & Ops \\
\hline Fire & Ministry of Internal Affairs & Ops \\
\hline $\begin{array}{l}\text { Evacuation and placement } \\
\text { planning }\end{array}$ & Ministry of Internal Affairs & Ops \\
\hline Security and traffic & Ministry of Internal Affairs & Ops \\
\hline Interment & Ministry of Internal Affairs & Ops \\
\hline Nutrition & Turkish Red Crescent & Ops \\
\hline Communications & $\begin{array}{l}\text { Ministry of Transport, Maritime } \\
\text { Affairs and Communications }\end{array}$ & Ops \\
\hline Transportation (infrastructure) & $\begin{array}{l}\text { Ministry of Transport, Maritime } \\
\text { Affairs and Communications }\end{array}$ & Ops \\
\hline Transportation & $\begin{array}{l}\text { Ministry of Transport, Maritime } \\
\text { Affairs and Communications }\end{array}$ & Ops \\
\hline
\end{tabular}


Key solution partners are responsible for the management of service groups and determine the roles and tasks of institutions and organizations they are to work with, the supportivepartners. All service groups should work in coordination with AFAD.

The supportive partners should take part in preparation of operational plans, support the execution of operations and meet the demands of the key partners, providing trained personnel, equipment, tools etc.

After the preparation of the national service plans, the key partner (ministry, institution or organization) in charge of the service group regularly evaluates the plan and makes updates in terms of personel, supplies, equipment etc. Plans should be revised and developed based on scientific and practical knowledge and experience drawn from the field in disaster and emergency situations, national and international trainingand exercises as well as technological developments.

There is a total of 10 ministries and an NGO (Turkish Red Crescent) assigned as key partners and over 100 of supportive partner institutions.

\section{National and local level plans and integration}

TAMP serves as a binding frame for conducting response work in disaster and emergency situations, capable of adapting to all scales at local and national levels.

Primarily, national level service group plans are prepared together with all the national level key and supportive partner institutions under the guidance of TAMP. Thus, the roles and responsibilities of institutions and organizations at the time of disaster are to be clear for a timely, a faster and more effective response.

The next step is the preparation of provincial disaster response plans and local level service group operation plans. Through these plans, just like in the national level, the roles and responsibilities are to be clarified at the local, settlement level in case of disaster and emergency. Service group operation plans at the local level are to serve as an attachment to provincial disaster response plans. The key partner of the service group in the national level prepares the local level service group plans through their own agencies at the local or regional levels with the help of the local/regional agencies of their supportive partners. It is important to note that two service groups are only established and work at a national level:1) National and International Donations In-Cash Service Group; 2) International Support and Cooperation Service Group (supplies and personnel etc.)

The key partner is responsible for the preparation of the national service group plans and carefully accomplishes these tasks:

- Thoroughly identify hazards and risks that can be faced during fulfillment of duties

- Within their service group responsibilities, identify and list all types of capacities and capabilities as strengths and resources

- Improve the coping capacity as much as possible in order to reduce the risks and damages that can be encountered 
- Guide and implement preparations for disasters and emergency situations at all levels

- Ensure cooperation and coordination among relevant institutions

- Update and extend all relevant information among stakeholders

- Organize and participate in training and exercises in their field of work

- Establish required sub-service groups and teams

- Organize and standardize teams' working procedures, principles and schedules at national and local levels

- Ensure effective involvement of private sector to provide necessary resources of all types.

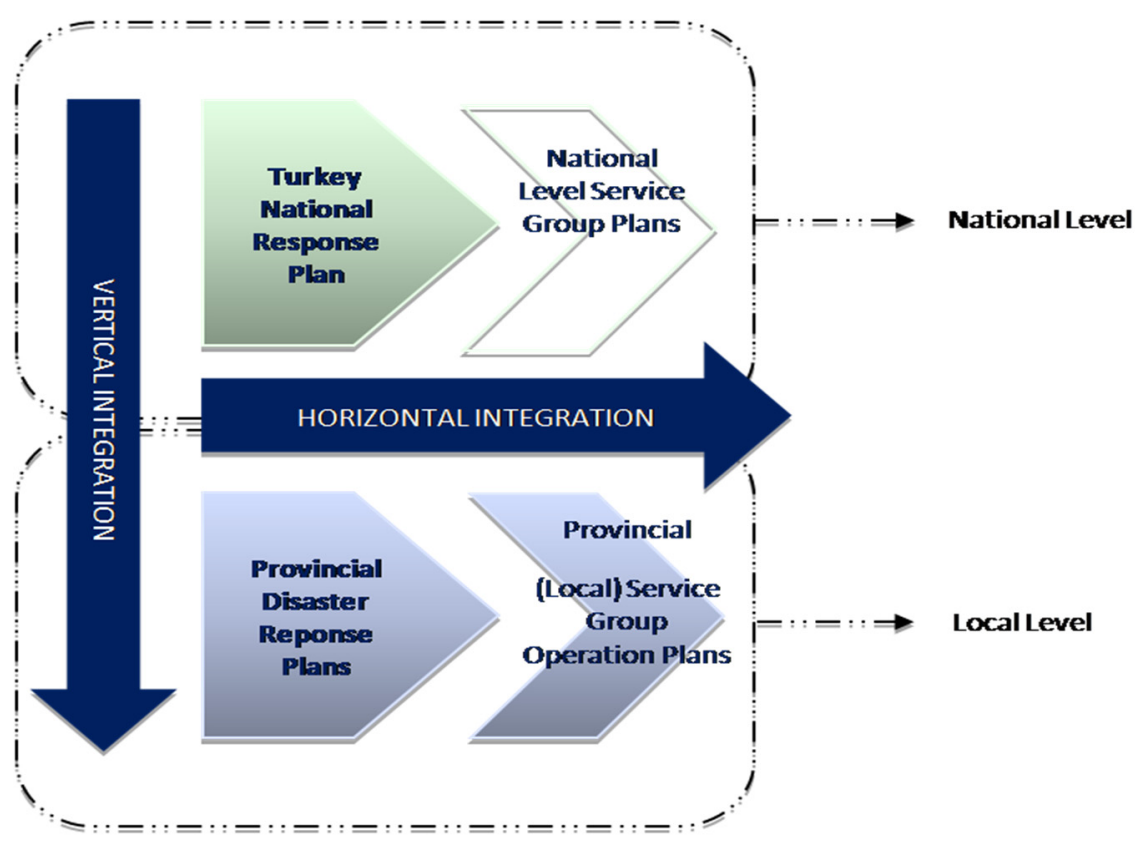

Figure 1: Vertical and horizontal integration of TAMP.

All 28 national level service group plans are prepared according to TAMP, and the groups work in the field in coordination and uninterrupted communication with Provincial Disaster and Emergency Management Centers established in Province Governorates. Each service group is informed about what other service groups may be demanding in detail beforehand. As other needs would surface in the face of disaster or emergency, the plan underlines the vitality of updating, experience sharing and capacity building, which in fact are obligations of duty.

All but two (donation and international support) national level groups plans are complemented with provincial level service groups, and their plan schemes are prepared at the national level. In the next step, local level authorities substantiate the plans with a special focus on hazards and vulnerability analysis 
of the province. The plan schemes are adaptable to respond the needs and challenges of each provinceaccordingly.

Every service group has field support personnel that would reach disaster zone immediately and help the response process begin through establishing necessary communication and connections between local and national levels. Depending on the severity of the situation, neighbouring provinces are to come to support the response work in disaster zone. In both cases, the personnel coming from outside the province or settlement, is informed about the system as all provinces use the same scheme, thus waste of time for adaptation and acclimation is avoided.

\section{Disaster response levels and management centers}

\subsection{Response levels}

Response levels are divided into four groups in terms of the degree of impact.

Table 2: Response levels.

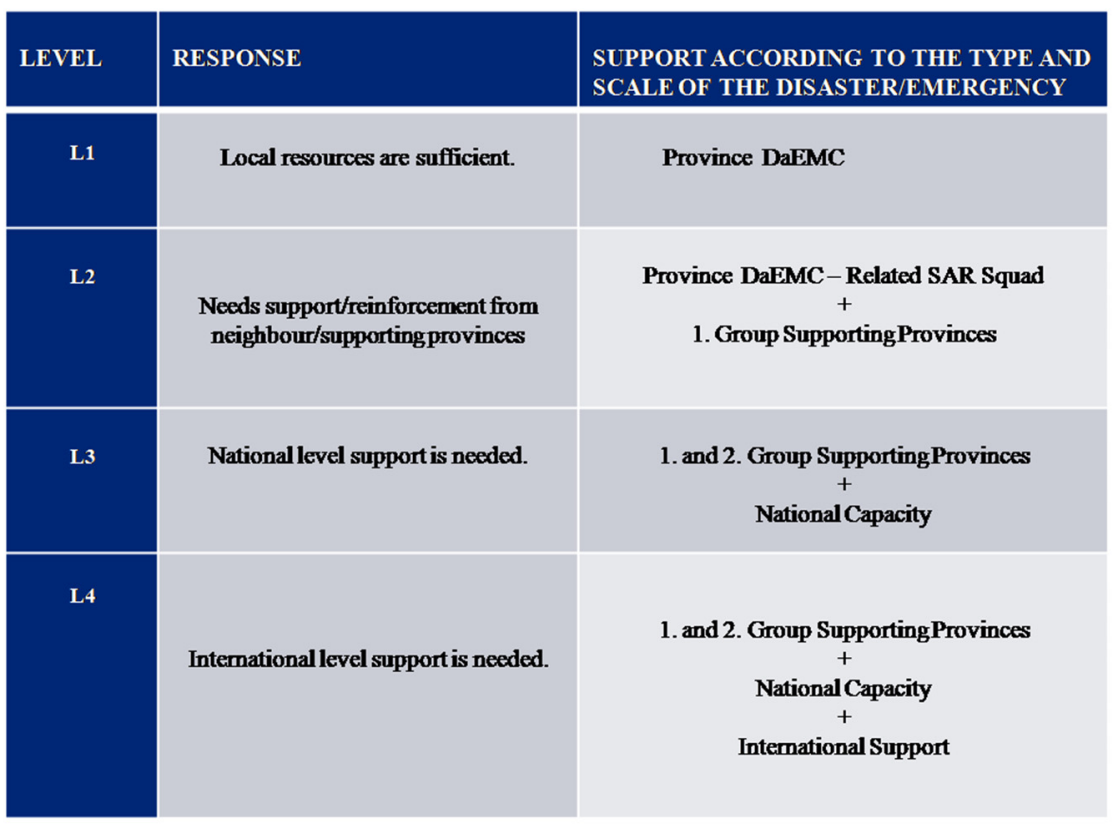

Level 1: Provincial Disaster and Emergency Management Center (DaEMC) is active and AFAD DaEMC follows and evaluates the situation. If needed AFAD informs the required service groups and may use their capacity for the requested assignment. 
Level 2: Provincial DaEMC is active, teams from supportive neighbouring provinces and regional Search and Rescue (SAR) brigades move to disaster zone without waiting for further orders. If needed, AFAD informs the required service groups and may use their capacity for the requested assignment.

Level 3: AFAD DaEMC is active, representatives from all service groups gather at Prime Ministry DaEMC. Teams from supporting provinces and regional Search and Rescue brigades move to disaster zone without waiting for futher orders, and national capacity is at full use.

Level 4: In addition to full national capacity used at Level 3, calls for international support are madeby the government.

\subsection{Disaster and emergency management centers and boards}

a) Disaster and Emergency High Council, comprised of Ministers, evaluates the information and suggestions from Disaster and Emergency Coordination Board, comprised of Undersecretaries of Ministries, and from national and international sources, determines the principles of political directives on relevant issues and establishes binding decisions for all levels.

b) Disaster and Emergency Coordination Board evaluates the information in case of disaster and emergency, determines necessary treatment measures, ensures the measures are applied and supervises the whole process. The Coordination Board also provides coordination among public institutions and with private and non-governmental organizations.

c) Prime Ministry DaEMC is set up on the order of the Prime Minister and under the chairmanship of AFAD President to ensure efficient response and coordination. DaEMCs are also established in key partner institutions to have uninterrupted contact and commmunication with both disaster zone and other authorities.

d) Provincial DaEMC works 24/7 under the chairmanship of a Deputy Governor, who is assigned by the Governor. The Provincial Disaster and Emergency Coordination Board is comprised of appointed and elected local public authorities. At times of a disaster, a high ranking AFAD official provides direct support and consultation required by the Governor in disaster zone and adequate number of field support personnel from AFAD assist local service groups. The key partner institutions also send field support personnel to disaster zone. Each service is coordinated by the deputy governor who heads the Provincial DaEMC under the supervision of Province Governor.

Thus, the national disaster response system is modelled in a triangle formed by a) Prime Ministry/AFAD DaEMC, b) DaEMCs of Key Partner Institutions, and c) Provincial DaEMCs. 


\section{Conclusions}

The national service group plans that are developed at ministrial and institutional levels form the "Service Model" for preparation of plans, coordination and respective field implementation. Each service group is to serve as a sub-model for the system, displaying an example and guideline for local level service group plans. The national response system is designed to give qualified support to the local response system, thus the disaster zone.

The relationship between the service groups at national and local levels is a parameter on the execution of integrated response function in disaster zone. The disaster and emergency response management at local level, on the other hand, is designed as an indigenous model to ensure effective implementation, and standardization, at the same time, countrywide. (See [7] for the international documents and work searched for field practice.)

\section{References}

[1] 2009 UNISDR Terminology on Disaster Risk Reduction.

[2] Gökçe, O., Özden, Ş. \& Demir, A., Türkiye'de Afetlerin Mekansal ve İstatistiksel Dağılımı Afet Bilgileri Envanteri, Ankara, pp. 1-4, 2008.

[3] Turkey Tenth National Development Plan 2014-2018, Efficiency in Disaster Management Report by Committee of Experts, 2014, p. 4.

[4] Oktay, F., Tetik, C., Gökçe, O. \& Çebi, G., New Disaster Management System at Turkey: A Case Study of Van Earthquake, p. 12, 2013.

[5] Republic of Turkey Prime Ministry Disaster and Emergency Management Presidency, Turkey National Disaster Response Plan, published at Official Gazette dated 3/01/2014, number 28871.

[6] Ninth Development Plan (2007-2013); Medium Term Programme (20132015); Rural Development Plan (2010-2013); National Earthquake Strategy and Action Plan (2012-2023); Integrated Urban Development Strategy and Action Plan (2010-2023); National Climate Change Adaptation Strategy and Action Plan (2011); Occupational Health and Safety Risk Assessment Guide.

[7] UN OCHA Coordination Tools; EU Civil Protection Mechanism; IFRC Code of Conduct; The Humanitarian Charter and Minimum Standards in Disaster Response (SPHERE Project); WHO/PAHO, Hospital Safety Index; INTOSAI, Accountability for and Audit of Disaster-related Aid. 